\title{
MIGUEL DE UNAMUNO: INTERSECCIONES ENTRE METAFÍSICA Y POLÍTICA
}

\author{
JOSÉ MANUEL IGLESIAS GRANDA \\ Instituto de Filosofía CSIC
}

\begin{abstract}
RESUMEN: Este estudio trata de poner de manifiesto que una adecuada comprensión del pensamiento y actuación políticos de Miguel de Unamuno requiere de un conocimiento profundo de la metafísica del autor. La evolución de su vida filosófica, íntimamente relacionada con su devenir existencial, marcó no solo su ideología sino también su forma de entender y hacer la historia y la sociedad. En este sentido se han detectado cuatro ejes de intersección entre política y metafísica. Aunque él mismo consideró que su principal compromiso político radicaba en sus escritos, su participación en la vida nacional fue decisiva. La maduración espiritual le llevó a abandonar los planteamientos utópicos del socialismo y a defender posiciones donde primase la dimensión espiritual del hombre. Gracias a ellas, don Miguel identificó con claridad el peligro tanto de los planteamientos fascistas como comunistas; plantando cara activamente a las manifestaciones de ambos en España. Pues, para él, la misión del país radicaba en la fundamental tarea de vivir y defender la loca filosofía del Sentimiento trágico de la vida.
\end{abstract}

PALABRAS CLAVE: España; historia; metafísica; política; Unamuno.

\section{Miguel de Unamuno: Intersections between Metaphisics and Politics}

ABSTRACT: The purpose of this project is to emphasize that an adequate comprehension of Miguel de Unamuno's political thinking and action requires a meticulous understanding of the author's metaphysics. The evolution of his philosophical life, intimately related to his existential growth, marked not only his ideology, but also his approach to understanding and making history and society. It that way, four intersection axis between politics and metaphysics have been discovered. Even though he himself regarded his writings as being his chief political commitment, the pundit's participation in the national life at the time, was crucial. Spiritual maturation led him to abandon the utopian methods of socialism, and to defend positions where the spiritual dimensions of mankind prevailed. Thanks to this, Mr. Unamuno undoubtedly identified the danger of both fascist and communist methods, actively defying displays of both in Spain. For him, the essence and purpose of the country, beyond all ideologies, lay in the cardinal duty of living and defending the mad philosophy of the Tragic sense of life.

KEY WORDS: history; metaphysics; politics; Spain; Unamuno.

\section{INTRODUCCIÓN}

El personaje de Miguel de Unamuno ha despertado desde siempre un gran interés en el ámbito social e intelectual. En vida gozó de importante repercusión 
tanto a nivel nacional como internacional y, una vez fallecido, un gran número de artículos y estudios se han publicado referentes a su filosofía y a su obra en general ${ }^{1}$. Aun así, el pensamiento y compromiso político del filósofo vasco siguen generando un cierto punto de controversia ${ }^{2}$.

Este artículo parte de un convencimiento clave que es el de que la acción y pensamiento políticos de don Miguel solo pueden entenderse desde una plena comprensión de su vida filosófica. Desde el principio, el compromiso social del rector salmantino estuvo transido de unos profundos convencimientos metafísicos; éstos impregnaban no solo sus escritos o conferencias sino todo tipo de iniciativa que de él saliese. Ahora bien, si algo caracteriza a Unamuno es el dinamismo de su trayectoria filosófica; sin duda, estamos ante un claro pensador de la vida ${ }^{3}$ que fue atravesando diferentes etapas o estadios a lo largo de su existencia.

Conocer y comprender esta evolución existencial y filosófica es fundamental para hacer justicia al Unamuno político y para entender, a su vez, los diferentes posicionamientos que fue sosteniendo en las diferentes etapas. En el presente estudio se tratará de llevar a cabo esta tarea. Para ello, se propone un marco categorial de cuatro ejes de intersección entre metafísica y política que permitirán entrever de una forma clara la realidad e importancia de la estrecha relación que ambas disciplinas guardan en nuestro autor ${ }^{4}$. Estos ejes surgen de la lectura atenta de la obra de Unamuno y de una aproximación detallada a su biografía y han de comprenderse desde un núcleo directivo constante: el pensamiento liberal de tintes libertarios que mantuvo a lo largo de toda su

1 Por lo que a la temática de este artículo se refiere, es fundamental tener en cuenta la valiosa recopilación y estudio del pensamiento político de Unamuno llevada a cabo por Elías Díaz. Vease: Díaz, E., Antología del pensamiento político de Unamuno, Tecnos, Madrid, 1965 y Díaz, E., Revisión de Unamuno, Tecnos, Madrid, 1968. Ambas obras han servido como guía en la elaboración de este estudio aunque no se subscriban sus tesis principales.

2 Los últimos meses de vida de don Miguel siguen despertando hoy día un gran interés. Unamuno es especialmente cuestionado por su comportamiento al final de la República y al comienzo de la Guerra Civil Española cuando apoyó el levantamiento del general Franco. A propósito de todo esto, el matrimonio Rabaté ha elaborado un valioso estudio; en él abordan de forma minuciosamente científica todos los escritos y datos relativos a este periodo. Vease: Rabaté, J. C. y Colette, En el torbellino, Marcial Pons, Madrid, 2018.

3 Alicia Villar ha tratado especialmente esta dimensión de la filosofía unamuniana. Vease: VILlar, A., "Una filosofía desde la vida: Unamuno y Ortega», en: Cuenta y Razón, 2006, pp. 13-20.

${ }_{4}$ Cada uno de estos ejes recoge un aspecto fundamental del pensamiento de don Miguel que claramente se relaciona con alguno de los posicionamientos políticos adoptados por el mismo. Se presentan como clave hermenéutica de cara a muchas actitudes del filósofo que, de primeras, pudieran parecer especialmente polémicas. Ya se ha hecho alusión a los últimos meses de su vida, pero tampoco debe olvidarse lo controvertido de su papel a lo largo de la II República. El citado matrimonio Rabaté así como el español Emilio Salcedo han realizado un importante trabajo biográfico con relación a Unamuno sin cuyo apoyo sería imposible este artículo. Vease: Rabaté, J. C. y Colette, Miguel de Unamuno: biografía, Taurus, Madrid, 2009; Rabaté, J. C. y Colette, Miguel de Unamuno (1864-1936) convencer hasta la muerte, Galaxia Gutemberg, Madrid, 2019 y SaLcedo, E., Vida de don Miguel, Anaya, Madrid, 1964. 
vida $^{5}$. El primero de ellos es el panteísmo-socialismo —clave para comprender al Unamuno joven-, el segundo se ha denominado como la dialéctica entre el yo profundo y el yo histórico, el tercero sería el quijotismo unamuniano y el cuarto: el individualismo cordial.

\section{El panteísmo-Socialismo del UnAmuno RegEneracionista}

Don Miguel nace y vive en un periodo especialmente convulso de la historia de España ${ }^{6}$. Después de atravesar una etapa caracterizada por el catolicismo practicante y el nacionalismo vasco ${ }^{7}$, nuestro autor llega a Madrid para comenzar sus estudios universitarios. Una vez en la capital, Unamuno rápidamente entra en contacto con el espíritu de pesimismo que comienza a invadir el país. El auge del nacionalismo y el colonialismo en el resto de potencias europeas

5 Este rasgo fundamental del pensamiento político unamuniano se hace ya presente en los albores de la carrera del intelectual. Antes de adherirse a la causa socialista, existe un Unamuno joven fuertemente influido por los escritos de Pi y Margall y las doctrinas postivistas. El pensamiento de este Unamuno aún inmaduro se caracteriza por la defensa del individuo frente a toda forma poder represor y absolutismo político o religioso que pueda coartar su libertad. Se muestra contrario al socialismo y a toda acción de las masas, al concebirlos opuestos al espíritu de acción individual y libre. Comprende el estado y su fuerza en la línea de un pacto entre las libertades individuales y señala con ahínco su carácter secundario con respecto al propio individuo.

A lo largo de toda su obra, este liberalismo libertario será un supuesto básico que se irá manifestando en diferentes direcciones según vaya evolucionando su vida filosófica. Sus principales características son: la soberanía del individuo, el carácter productivo de la lucha y la no delegación de la conciencia. Para una mayor profundización en este aspecto véase: Cerezo Galán, P., Miguel de Unamuno, ecce homo: la existencia y la palabra, Ediciones Universidad de Salamanca, Salamanca, 2016, pp. 150-166.

6 Unamuno nació en Bilbao en 1864. Por aquel entonces, atrás quedaban las dos Guerras Carlistas — con causa fuertemente arraigada en su tierra- y el reinado de Isabel II estaba próximo a llegar a su final. Apenas cuatro años después de su nacimiento, tiene lugar la Gloriosa Revolución de 1868. Isabel II es depuesta del trono. Rápidamente, se sucedieron el breve amago de reinado de Amadeo de Saboya y la posterior I República. El país se sumió en una inestabilidad ingobernable, en buena parte debida al caos territorial en que derivó el proyecto federalista republicano; en ese contexto, cobra protagonismo la figura del estadista e intelectual Cánovas del Castillo. Éste diseña e implanta un modelo político a fin de hacer posible la gobernabilidad del país: la Restauración.

En 1873, estalla la III Guerra Carlista. El ya antiguo movimiento que la propicia bebía de las reticencias al liberalismo y al centralismo, preponderantes durante el reinado de Isabel II. La invicta villa de Bilbao, una de las enseñas del liberalismo en España se convierte en un foco clave para los carlistas, muy fuertemente arraigados en la Euskadi rural. Sin embargo, la causa carlista es derrotada y se consolida el reinado de Alfonso XII, haciéndolo con él las tendencias centralistas. Para una mayor profundización en el contexto histórico y biográfico véase: Vicens Vives, J., Aproximación a la historia de España, Vicens Vives, Barcelona, 2003, pp. 155 y ss. y Salcedo, Emilio, o.c., pp. 39-41.

7 Para explorar con mayor profundidad este periodo, que coincide con la adolescencia de Unamuno y los años previos a su llegada a Madrid, véase su relato autobiográfico: UnAmUNo, M., Recuerdos de niñez y mocedad, Alianza Editorial, Madrid, 2012, p. 150 y ss. 
se traduce en España en un creciente sentimiento de inferioridad que poco a poco irá desencadenando reacciones del todo diversas: desde las exaltaciones de la patria y de las hazañas del pasado de los sectores más conservadoras hasta las reflexiones más críticas de los que más adelante serían conocidos como regeneracionistas ${ }^{8}$. Nuestro intelectual se verá claramente influido por este panorama que dará contenido a buena parte de las conversaciones y debates que mantiene con sus amigos y condiscípulos ${ }^{9}$. Por tanto, puede decirse que las primicias de la carrera intelectual de Unamuno están marcadas por el regeneracionismo. Aparte de eso, el joven Miguel también se empapará en Madrid de las doctrinas positivistas que en aquel momento bullían en España. Éstas jugarán un papel importante en sus primeras formas de pensar la política, el estado y la sociedad.

Ahora bien, dentro de las ideas políticas no es solo la cuestión española la que preocupa a don Miguel sino también el socialismo. Su compromiso socialista arranca al principio de su carrera, después de un breve periodo de un liberalismo radical cercano al anarquismo ${ }^{10}$. En $1884^{11}$, el intelectual ingresó en la Agrupación Socialista de Bilbao y destacó por la publicación asidua de artículos en el semanario La Lucha de Clases. Aunque nunca fue un marxista ortodoxo $^{12}$, los principios revolucionarios sí que calaron en su pensamiento. Blanco Aguinaga lo refleja con claridad: «No solo fue Unamuno miembro del partido socialista, sino que escribió en marxista hasta la segunda mitad de 1896 y luchó

8 José Álvarez Junco trata con detalle en su libro Mater Dolorosa los diferentes tipos de manifestaciones nacionalistas que tuvieron lugar en España en esta última fase del siglo XIX. Vease: Álvarez Junco, J., Mater Dolorosa, Taurus, Madrid, 2001, pp. 445 y ss.

9 Especialmente cabe destacar aquí la amistad que Unamuno mantiene con Angel Ganivet — quien será luego considerado predecesor de la generación del 98-. Precisamente, en torno al año del Gran Desastre se publica en el diario El Defensor de Granada la interesante correspondencia entre ambos intelectuales en la cual se trata abiertamente la cuestión española. Ésta sería luego publicada en forma de libro bajo el título El porvenir de España: véase: Ganivet, Á. y Unamuno, M., El porvenir de España, Espasa Calpe, Madrid,1940. Trato de forma más extensa la relación Unamuno-Ganivet en el libro Sentir y Pensar la historia con Miguel de Unamuno; véase: Iglesias Granda, J. M., Sentir y pensar la historia con Miguel de Unamuno, Apeiron Ediciones, Madrid, 2019, pp. 40 y ss.

10 El derecho y la fuerza, conferencia pronunciada en 1887, recoge en buena medida las ideas liberal-libertarias de este joven Unamuno anterior al socialismo. Ahora bien, buena parte de esas ideas, aun inmaduras, que en ella se exponen resultarán fundamentales para comprender a todo el Unamuno posterior. Vease: UnAmuno, M., El derecho y la fuerza, Luján Palma, E. (ed), S. L. Punto Rojo Libros, Sevilla, 2017.

${ }_{11}$ Biográficamente, 1884 es el año en que el filósofo vasco se doctora y vuelve a su tierra. Allí permanecerá hasta que finalmente en 1891 gane una cátedra de griego en la Universidad de Salamanca. Vease: Salcedo, E., o. c., p. 53.

12 Cerezo Galán señala como, aun en la etapa de mayor fervor socialista, la matriz del pensamiento de Unamuno estaba fuertemente determinada por los principios liberales y por una religiosidad reformada. Principios ambos que le harán presentar resistencias a las tesis marxistas más revolucionarias y contrarias a la dimensión espiritual. Vease: Cerezo GaLÁn, P., Miguel de Unamuno, ecce homo: la existencia y la palabra, Ediciones Universidad de Salamanca, Salamanca, 2016, p. 174. 
por mantenerse en sus posicionamientos marxistas incluso en el momento de la crisis» ${ }^{13}$.Y el mismo don Miguel escribió estas palabras:

«Me puse a estudiar la economía política del capitalismo y el socialismo científico a la vez, y ha acabado por penetrarme la convicción de que el socialismo limpio y puro, sin disfraz ni vacuna, el socialismo que inicio Carlos Marx con la gloriosa Internacional de trabajadores, y al cual vienen hoy a refluir corrientes de otras partes, es el único ideal hoy vivo de veras, es la religión de la Humanidad» ${ }^{14}$.

Estas convicciones generarán polémica en la conservadora Salamanca, ciudad en la que había obtenido su primera cátedra. Además, Unamuno se carteará con Pablo Iglesias, llegando a manifestarle el deseo de formar una agrupación socialista en la ciudad del Tormes ${ }^{15}$. Todo esto hará que su nombre vaya adquiriendo fama a nivel nacional.

En torno al casticismo es la principal obra unamuniana correspondiente a este periodo y su gran peso filosófico la convierte en la mejor fuente para comprender este primer eje de intersección. Unamuno se entiende ahora a sí mismo y al conjunto de la realidad partiendo del panteísmo ${ }^{16}$. Estamos ante una cosmovisión donde la vida humana y la sociedad entera son momentos puntuales en el desarrollo de la vida de un Todo, que el vasco ha denominado Hecho y que está definido por una legalidad determinada y un dinamismo intrínseco que él mismo va desarrollando y dando de sí a lo largo del tiempo. Ahora bien, con la peculiaridad de que es en la vida humana y en la sociedad por ende donde ese Hecho toma conciencia de sí.

Podemos decir que el filósofo hace una propuesta regeneracionista de un claro cariz metafísico en esta obra y es que aborda los principales problemas de la vida social de la España del momento desde esta forma de pensar. Introduce el término "castizo» en reacción al son reinante en los ámbitos culturales de la España del momento ${ }^{17}$ y se dedicará a analizar lo castizo castellano para averiguar

13 Vease: Blanco Aguinaga, C., El socialismo de Unamuno: II Congreso Internacional de Hispanistas de Nimega, en: Revista de Occidente, 1965.

14 Fragmento de una carta a Valentín Hernández que el mismo Blanco Aguinaga cita en la publicación previamente citada: Blanco Aguinaga, Carlos, o. c.

15 Para una mayor información véase: Rabaté, J. C. y Colette, Miguel de Unamuno: Biografía, Taurus, Madrid, 2009, pp. 153 y ss.

16 Su pensamiento de esta época es una ecléctica síntesis de las filosofías de Hegel, Espinosa, Spencer, Marx, Herder, Comte, Darwin y el krausismo; y en ella priman elementos que derivan de una visión monista de la realidad, completada con factores krausistas, positivistas, evolucionistas e historicistas que apuntan a una laxa dialéctica universal. Para alcanzar un detalle mayor véase: García-Baró, M., Sentir y Pensar la vida, Trotta, Madrid, 2012, p. 60; y: García-Baró, M., «Dos Unamunos que son él mismo», en: Revista del Centro de Investigación la Salle Mexico D. F., 2016.

17 Ya hemos hablado de la peculiar fiebre nacionalista que se despierta en España a finales del XIX y que se materializa en eventos tales como la celebración de centenarios conmemorativos de personajes célebres del pasado y en una clara cerrazón a todo lo exterior al entenderlo como perturbador de las esencias de la nación. Vease: Álvarez Junco, J., o. c., pp. 380 y ss. e Iglesias Granda, J. M., o. c., pp. 22 y ss. 
hasta dónde llega esto y hasta dónde lo clásico o eterno, íntimamente relacionado con el ideal de Humanidad krauso-socialista que anhelaba por aquel tiempo.

Una de las primeras cuestiones que nuestro intelectual aborda desde esta cosmovisión es la entonces popular polémica de la ciencia española ${ }^{18}$, pero no entra en ella, sino que va inteligentemente al fondo de la cuestión: ¿Qué es ciencia? Y ¿qué sentido tiene eso de ciencia española?

Don Miguel señala que aunque la ciencia lleva dentro de sí algo pre-científico y teñido de materia nacional, ésta va más allá del sentido común y, por lo tanto, no tiene nación: «aunque la idea está condenada al espacio y al tiempo, la ciencia moriría si poco a poco no fuese redimiéndose del ambiente, de la lengua vulgar, y creando su propio tecnicismo universal» ${ }^{19}$. La labor de la ciencia es, para Unamuno, la de ir rompiendo la «cáscara» de los hechos para penetrar en su interior donde se halla la explicación de su sentido. Siguiendo su metafísica, la ciencia buscaría hacer consciente la evolución de lo eterno que ha dado lugar al hecho en sí... rehacer los hechos a fin de obtener para la conciencia «hechos rehechos y re-rehechos». Al generalizar, la ciencia penetra en la entraña que explica la manifestación de cada hecho y deja que los hechos consecutivos se asocien gracias a sus nimbos ${ }^{20}$, de modo que el hecho particular aislado se descubre como un hecho general, como una nueva expresión de una ley ${ }^{21}$.

Con todo esto Unamuno no niega que el instinto científico del hombre se valga de las lenguas castizas, no obstante, para él la labor de la ciencia radica en pinchar los viejos términos para que dejen escapar su jugo intra-lingüístico ${ }^{22}$. Se trata más de una tarea de profundización vertical y universal hacia la intrahistoria que de expansión horizontal en los diferentes pueblos particulares.

Lo mismo piensa del arte, que aun siendo para él más castizo que la ciencia, entiende también que existe un arte eterno, universal, clásico que va mucho más allá de cualquier costumbrismo.

Por otra parte, el desarrollo de la dialéctica entre «tradición» y «presente momento histórico» constituye otro de los núcleos principales de los ensayos de En torno al casticismo. Para don Miguel, hay algo que sirve de sustento al perpetuo flujo de las cosas. Mientras pasan los sistemas, las escuelas y las teorías, va

18 Ésta se desarrolló a lo largo de las tres últimas décadas del siglo XIX y enfrentó a intelectuales de los sectores conservador (Laverde y Menéndez y Pelayo) y krausista (Azcárrate). Se discutía la afirmación de los sectores liberales de que en España no se había desarrollado una ciencia propia debido al fuerte arraigo y poder de la Iglesia Católica. Para una mayor profundización véase: SuAnces Marcos, M., Historia de la Filosofía Española Contemporánea, Síntesis, Madrid, 2006, pp. 161-205.

19 Unamuno, M., En torno al casticismo, Cátedra, Madrid, 2017, p. 139.

20 Los nimbos son para Unamuno halos o estelas de los diferentes hechos a partir de los cuales recibimos siempre algo más que el hecho aislado.

${ }^{21}$ El hecho, en su nimbo, es percibido por la mente como un momento de la vida — sujeta a leyes- de ese Hecho que es el todo. En nosotros el Hecho toma conciencia de sí, digamos que el Hecho se nos da, nos abre sus entrañas, es por ello por lo que Unamuno - haciendo el paralelismo con la doctrina cristiana de la gracia divina- habla de gracia humana.

22 Unamuno, M., En torno al casticismo, Cátedra, Madrid, 2017, pp. 136 y ss. 
formándose el sedimento de las verdades eternas. «Sobre el suelo compacto y firme de la ciencia y el arte eternos corre el río del progreso que le fecunda y acrecienta ${ }^{23}$. Todo suceso histórico vivido por la mente deposita silenciosamente su núcleo esencial en el hondón del alma. Hay todo un proceso de sedimentación constante, aunque lenta y tamizada, de la realidad en nosotros. La realidad, el Hecho, se va desdoblando por medio de ese continuo poso $^{24}$ en nuestra interioridad.

Efectivamente hay un «presente momento histórico»; pero si lo hay, es gracias a la tradición del presente, que es la sustancia de la historia... pasado asimilado, hecho sustancia nuestra. Se trata de una vida intrahistórica, silenciosa y continua, como el fondo vivo del mar, que se diferencia de los «presentes momentos históricos» que vendrían a ser como el continuo ir y venir de olas que acontece en la superficie de todo océano. Es fundamental comprender este concepto de vida intrahistórica si de veras queremos llegar al fondo de esta obra que analizamos. No es la tradición muerta que se busca en libros y papeles, que llena los manuales de historia y las líneas del tiempo; sino que se trata de la Vida misma que hace posible que cualquier hecho histórico tenga lugar en su superficie ${ }^{25}$. Para Unamuno es en esta tradición donde hemos de buscar la esencia y originalidad del hombre, por ello, para conocerla bien, es necesario zambullirse en ella sin intentar agarrarse a los ruidosos hechos históricos pasados y presentes. Pero además, y en contraposición con las lecturas dominantes en su tiempo, este concepto de tradición aleja de todo particularismo diferenciador e invita a buscar lo universal que existe en el corazón de todos los hombres, la Humanidad, el pueblo nuevo: «La humanidad es la casta eterna, sustancia de todas las castas, que se hacen y deshacen como las olas del mar; solo lo humano es eternamente castizo» ${ }^{26}$.

Aborda también el concepto de patria a partir desde esta cosmovisión: la vida misma del Hecho y su legalidad intrínseca harían espontáneo el surgimiento de las patrias y las naciones. El contrato social es para Unamuno inmanente al Hecho mismo y surge de forma natural a partir de la comunidad de intereses y la presión de los diferentes agentes ${ }^{27}$. La historia misma va haciendo a los pue-

23 Ibid., p. 145.

24 Poso que no es otra cosa que el valor eterno que contienen los hechos históricos cotidianos, y que se organiza, habitualizado, contribuyendo a crear un fondo de continuidad en forma de verdades permanentes en nosotros.

25 Unamuno tiene aquí especialmente presentes a aquellos que después de la Revolución de 1868 creían que iban a ser capaces de cambiar el país súbitamente. La instauración de la I República es, en palabras del profesor salmantino, un mero hecho ruidoso y superficial que está lejos de la vida intrahistórica de la mayoría de los hombres que forman el país. Vease: Unamuno, M., En torno al casticismo, Cátedra, 2017, pp. 145 y 146.

26 Unamuno, M., En torno al casticismo, Cátedra, 2017, p. 155.

27 Nuestro filósofo se da cuenta de que sin una comprensión de la necesidad de la unidad para el bien vivir es imposible sustentar una patria o nacionalidad. Por tanto, solo es cuestión de que las mentes capten la necesidad que la realidad impone... de que se hagan con la estructura misma del Hecho vivo en el que viven y que les lanza a vivir juntos si de veras quieren hacerlo prósperamente. 
blos y la lengua juega para don Miguel un papel importantísimo en todo este periodo $^{28}$. Unamuno tiene claro que España no se formó por imposición, sino por un proceso en el que la misma realidad se fue imponiendo y uniendo a los que de facto se necesitaban para vivir mejor ${ }^{29}$; no hubo para él una castellanización, sino una españolización en la que tanto Castilla ${ }^{30}$ como los demás pueblos fueron adquiriendo rasgos de los demás y así formar una unidad mayor.

Este eje de intersección prevalecerá desde la etapa universitaria hasta la crisis de 1897, aunque como anteriormente se ha señalado dejará huella en las cosmovisiones posteriores ${ }^{31}$. $\mathrm{Y}$ es que sería imposible acotar en el tiempo ninguno de estos ejes.

\section{DiALÉCTICA ENTRE EL «YO PROFUNDO»Y EL «YO HISTÓRICO»}

La preocupación acerca de la relación entre la profundidad personal y la faceta más público-política del yo es una constante en el pensamiento de Miguel de Unamuno ${ }^{32}$. A la vez que su metafísica va evolucionando, irá el intelectual afrontando este problema de maneras diferentes y desde diferentes puntos de vista. En este trabajo ${ }^{33}$ la abordaremos en tres alturas diferentes: Paz en la Gue-

28 Ibid., p. 162.

29 Unamuno coincide aquí con las tesis del historiador José Antonio Maravall quien estudió en profundidad la génesis de la idea de España en la Edad Media. Vease: MARAVALL, J. A., La idea de España en la Edad Media, Centro de Estudios Constitucionales, Madrid, 1981, pp. 521-523.

30 No obstante, don Miguel le reconoce a Castilla el potencial unificador, al ser capaz de dar a todos los pueblos un ideal y una misión común: la evangelización del Nuevo Mundo. Como clave regeneracionista, insta a no poder la atención en la misión e ideales del pasado sino a concentrarse en aquel potencial/vida primigenio (fondo intrahistórico de lo español) donde moran las fuerzas que encarnaron aquellas ideas y que pueden encarnar otras. Para una mayor profundización en este aspecto véase: IgLesias Granda, J. M., Sentir y pensar la historia con Miguel de Unamuno, Apeiron Ediciones, Madrid, 2019, pp. 30-39.

31 Hemos tomado En torno al casticismo como tratado principal de esa filosofía del primer Unamuno, sin embargo, la información aportada podría completarse de forma fructífera consultando los artículos de don Miguel en el noticiero vasco La lucha de clases. Vease: Unamuno, M., Artículos inéditos de la Lucha de clases, Ereño Altuna, J. A. (ed), Milenio Beta III, Bilbao, 2002.

32 Ésta es una preocupación típicamente contemporánea; es en este periodo de la historia cuando se comienza a afianzar la idea de la existencia de un yo interno, de una identidad personal a la que se oponen la sociedad y la historia en su conjunto. Comienza el auge del ideal de autenticidad y con él se empiezan a desarrollar en toda Europa las denominadas políticas del reconocimiento. Las ideas de Rousseau jugarán un papel importante en todo este proceso. Vease: TAYLOR, Ch., The Ethics of Authenticity, Harvard University Press, Cambridge, 1992, p. 29 y Fukuyama, Francis, Identidad, Deusto, Barcelona, 2019, pp. 64 y ss. Don Miguel de Unamuno, que vive a caballo de los siglos XIX y XX se hace eco de esto, aunque en su caso desde una perspectiva metafísica y existencial fuertemente influida por Sören Kierkegaard.

33 Pedro Cerezo Galán señala en su estudio acerca de la recientemente editada conferencia El derecho y la fuerza la presencia germinal de esta problemática en la forma de una antinomia entre individuo y sociedad. Vease: Cerezo Galán, P., Miguel de Unamuno, Ecce homo: la existencia y la palabra, Ediciones Universidad de Salamanca, Salamanca, 2016, p. 165. 
rra, del Unamuno joven; Nicodemo el Fariseo, del Unamuno post-crisis y Cómo se hace una novela del Unamuno del destierro.

\subsection{Paz en la Guerra y el Unamuno joven}

Si bien considerábamos En torno al casticismo como el tratado de filosofía del Unamuno joven, Paz en la Guerra es la obra literaria por excelencia de esta época $^{34}$. Don Miguel encarna sus ideas en una ficción histórica que traslada al lector al Sitio de Bilbao que tuvo lugar en el marco de la III Guerra Carlista. Toda la primera metafísica unamuniana entra en acción y de una manera muy especial los conceptos de «historia» e «intrahistoria», de «tradición» y «de presente momento histórico ${ }^{35}$ : la vida profunda que se manifiesta en los sencillos, que no se hacen preguntas y que resignadamente viven felices es el fundamento y matriz de la historia... esa vida intrahistórica e interior lo sostiene realmente todo aunque se vea alterada por hechos ruidosos de la historia, que suelen ser protagonizados por aquellos que se creen con poder para manipular y cambiar de la noche a la mañana el orden intrínseco de una vida que no conocen, que les precede y que sin darse cuenta les arrastra a ellos también.

Ricardo Gullón ${ }^{36}$ nos señala cómo en la obra aparecen dos planos invertidos, el primero es el fondo histórico, que se corresponde con la guerra en sí. A éste pertenecen las figuras de generales, políticos y clérigos, que unamunianamente podríamos definir como «bullangueros», y que creen escribir la historia con sus «ruidosos hechos de cartón piedra» ${ }^{37}$. El segundo plano es el intrahistórico, el decisivo para el autor, en él pone sus mayores energías y a él nos enfoca continuamente tratando de hacernos ver su importancia decisiva en el transcurrir de la historia.

34 El propio filósofo vasco tiene una gran consideración hacia esta obra, señalando en más de una ocasión el tiempo - entre siete y doce años-y trabajo que le tomó escribirla. En ella vierte muchos de sus recuerdos de juventud, pero también esconde un gran trabajo de campo. Su correspondencia con Pedro Múgica — paisano suyo afincado en Berlín- nos permiten hacernos una idea del significado de esta obra para su autor. Vease: Fernández Larraín, S. (ed), Cartas inéditas de Miguel de Unamuno, Zig-Zag, Santiago de Chile, 1965, pp. 246 y ss; y también: Unamuno, M. de, Obras Completas VIII, Escelicer, Madrid, 1966, p. 1192. O las palabras del propio Unamuno en: UnAmuno, M., «Un artículo más» en: Sotelo VÁzouez, A. (ed), Miguel de Unamuno: Artículos de las noticias de Barcelona, Lumen, Barcelona, 1993, p. 192.

35 Muy posiblemente la redacción de los ensayos de En torno al casticismo (1895) fuese simultánea al proceso de elaboración de esta novela. En las citadas cartas a Múgica habla de todo su trabajo recogiendo datos de todo tipo acerca de los carlistas y la guerra convencido de que ellos pintaban la guerra mejor que todo tipo de documento oficial o convencionalismo. Vease: Cartas inéditas de Miguel de Unamuno, Zig-Zag, Santiago de Chile, 1965, p. 119.

36 Gullón, R., Autobiografías de Unamuno, Gredos, Madrid, 1964, p. 27.

37 Estas expresiones son muy utilizadas por don Miguel en esta primera época, sobre todo en su obra: En torno al casticismo. 
En esta novela, Unamuno trata de narrar cómo una familia tradicional vasca - afincada en Bilbao- vive la última de las contiendas carlistas ${ }^{38}$. Hay una clara intención de poner de manifiesto lo que él considera que son las castas históricas frente a la verdadera casta de la humanidad universal. La familia está compuesta por un matrimonio y su único hijo, los cuales ven interrumpida su simple pero pacífica y plena existencia con el devenir de estos acontecimientos. Audazmente, don Miguel pretende reflejar cómo la cosmovisión sencilla ${ }^{39}$ de estas gentes les permite llevar una vida totalmente digna y gratificante - a pesar de las estrecheces; una existencia en íntima conexión con el latir de la Vida misma y con toda la naturaleza, pero no inmune a las perturbaciones de historia y del devenir político del momento. Pedro Antonio y Josefa Ignacia crían a su hijo (Ignacio) en la tranquilidad y recogimiento de su chocolatería; en medio de la rutina, la humildad y el cariño familiar. Sin embargo, ese entrañable hogar — casi mítico o atemporal- es también penetrado por los intereses políticos que mueven a los diferentes bandos que llevan el control de la sociedad. Y lo es en grado tal, que es imposible discriminar uno de los otros: el mismo hogar es escenario de reuniones entre viejos carlistas y el núcleo familiar se encuentra prácticamente abierto a las palabras y consejos — para nada neutros- del sacerdote de turno que no duda en alentar al rebaño a revolverse a favor de una causa que es suya pero no de ellos. Pedro Antonio lleva también en su corazón las espinas de la anterior contienda, no le movilizan ni le inquietan, pero se manifiestan latentes en los diferentes acontecimientos familiares, y de esa manera van también dando forma al hogar. Y es que la misma lógica histórica -el hecho de cartón piedra, el polvo de hecho- es indiscriminable para ellos de la paz intrahistórica en la que viven inmersos: en el fondo, es también parte de su paz. Por esta razón, el hogar de Pedro Antonio se moviliza con la guerra, lo mismo que se movilizan los millares de familias de los caseríos rurales $^{40}$. No es que entiendan ni luchen una guerra propia ${ }^{41}$, su actitud es más bien la de que quien se resigna ante lo que toca sin cuestionarlo ni preguntarse por qué. Ahora bien, todo esto tiene lugar porque los verdaderos interesados en la guerra habían penetrado en esa vida intrahistórica o incluso provenían de ella... no eran un agente extraño, sino - como antes se dijo- también formaban parte de esa paz.

Estamos ante una novela de tal profundidad que no es para resumir en pocos líneas: le requiere mucho esfuerzo e imaginación al literato expresar las

38 Caudet, Francisco, «Introducción a Paz en la Guerra», en: Caudet, Francisco (ed.), Paz en la Guerra, Cátedra, Madrid, 2018, p. 64.

39 Libre de toda duda y de toda turbación existencial.

40 «Cómo no iba a valer la vida para aquellos hombres la lucha contra los innovadores que deseaban acabar con la calma y la lenta paz de sus vidas, precipitándoles en una agitación cuya finalidad se les escapa. ¡Claro que el combate puede parecer inevitable y santo!». Gullón, R., Autobiografías de Unamuno, Gredos, Madrid, 1964, p. 35.

${ }_{41}$ Como audazmente quiere reflejar Unamuno con el joven Ignacio. Para una mayor profundización en esta idea vease: Pérez de la Dehesa, R., Política y sociedad en el primer Unamuno, Ariel, Barcelona, 1973. 
ideas que el filósofo puede recoger en un párrafo. Pero yéndonos a la filosofía, con todo esto podemos ver ya claramente las ideas principales: para don Miguel prima ahora un yo profundo entendido como intrahistoria; como la vida universal de la Casta Humana que late en todas las castas y prevalece sobre los hechos históricos que relatan las crónicas ${ }^{42}$. No hay una primacía del individuo - de un yo existencial— sino del Pueblo del que cada persona es un mero punto. No obstante, sobre esta Casta Humana se ciernen los vientos y el oleaje de los hechos históricos; y éstos la penetran y agitan hasta tal punto que son indistinguibles de ella... y la mueven, llevándola a donde ella ni sabe ni quiere.

La obra termina con el padre solo, viudo por la pena y sin hijo por la guerra; pero de nuevo en la misma vida intrahistórica que tuviera... sin comprender, o sin alcanzar a hacerlo suficientemente. Empero, Unamuno deja abierta una esperanza ${ }^{43}$ : la vida del intrahistórico y del intelectual pueden ser aliadas, siempre y cuando el primero se deje conmover y el segundo no se aísle de la vida real. El intelectual al tomar conciencia de esa realidad intrahistórica siente el deber de denunciar los «hechos ruidosos» y de defender al intrahistórico de ellos. Él no vive ni vivirá la paz del que está espontáneamente inserto en la vida del $\mathrm{Hecho}^{44} \ldots$ pero sí puede contemplar y admirarse de esa profunda dimensión intrahistórica.

\subsection{Nicodemo el fariseo y el Unamuno post-crisis}

Nicodemo el fariseo ocupa un lugar central entre los millares de artículos y conferencias unamunianas, ya que refleja a la perfección la transformación que tiene lugar en el pensamiento del filósofo vasco tras la crisis de $1897^{45}$. A partir de ese momento, la finalidad de la vida individual tomó una importancia clave para don Miguel, produciéndose un abandono de aquel ideal panteístasocialista de «Humanidad». Ahora bien, esto no significa que abandonase las preocupaciones sociales a favor de las espirituales ${ }^{46}$, sino más bien que estas se-

42 Esta vida late en el hogar de Josefa Ignacia, al igual que late en los caseríos de Vizcaya rural.

43 Para profundizar en esta idea véanse los siguientes estudios: SANCHEZ Barbudo, A., Estudios sobre Unamuno y Machado, Guadarrama, Madrid, 1959, p. 88 y Blanco Aguinaga, C., "Interioridad y exterioridad en el joven Unamuno», en: Nueva revista de Filología Hispánica, VII, 1959.

${ }_{44}$ El que está inserto en el hecho posee una mirada sub specie aeternitatis, como señala el propio Unamuno haciéndose eco de las doctrinas de Spinoza.

${ }_{45}$ La grave enfermedad y posterior muerte de su tercer hijo, sumen a Unamuno en una crisis que dará un giro radical a su pensamiento. Ésta cobra especial fuerza en marzo de 1897, en esos momentos el intelectual se encontrará cara a cara con el —por el denominado- «misterio de la Esfinge», o sea, la cuestión del sentido y finalidad de la vida.

46 En este ensayo no se comparte la tesis del filósofo del derecho Elías Díaz, quien señala en Unamuno un abandono de las preocupaciones y de la lucha social a favor de un «espiritualismo absolutizante». Vease: Díaz, E., Revisión de Unamuno, Tecnos, Madrid, 1968. Y es que, don Miguel continúo profunda y activamente preocupado por realidad sociopolítica española; cabe recordar que fue candidato tanto al Concejo de Salamanca como a las Cortes en más 
gundas le condujeron a pensar en nuevos horizontes de transformación social. Tampoco reniega de las ideas socialistas, sino que comienza a entenderlas de una nueva perspectiva según la cual el progreso social sería la base del verdadero progreso individual, de la ascensión a Dios por $\mathrm{Cristo}^{47}$.

$\mathrm{El}$ «hombre íntimo» se vuelve crucial para nuestro autor, el cual comienza a sostener la dualidad para comprender al sujeto moderno, escindido e incapaz de restaurar una comunicación armónica entre interioridad y exterioridad. La infancia se convierte en el momento casi mítico en el que el «yo» se veía libre de todas las capas superpuestas socialmente y que le impedían aflorar en toda su potencialidad ${ }^{48}$, por lo tanto, la imagen del niño se vuelve un horizonte para Unamuno. La sociedad impone al hombre múltiples ataduras ${ }^{49}$ que le van haciendo cada vez más complicado vivir auténticamente su ser. Las propias decisiones sociales y políticas del día a día crean una trama cada vez más densa que impide que emerja la auténtica realidad personal.

Para el Unamuno actual, el hombre no es solo el producto histórico de sus acciones y de su entorno: hay un hombre interior, intrahistórico y eterno... ajeno a la historia. Por eso, el hombre puede renacer de todos los convencionalismos sociales con la ayuda del plus de la fe. Esa metanoia consistiría en recuperar el yo interior dejando a un lado — como quien pela una cebolla - todos los añadidos que la historia y la sociedad han ido pegando ${ }^{50}$.

La dialéctica historia-intrahistoria desarrollada de En torno al Casticismo es llevada a consecuencias mucho más radicales ${ }^{51}$. Ya no se trata de un volver al interior y un zambullirse en lo impersonal de la tradición eterna; sino que la tradición se revela ahora como el fondo no sólo de cada pueblo, sino de cualquier

de una ocasión, llegando a ser concejal y diputado. Además fue especialmente crítico con el reinado de Alfonso XIII — siendo censurado y condenado por delitos de imprenta en 1920Para mayor profundización consultar las biografías ya citadas: RABATÉ, J. C. y Colette, o. c., p. 220 y ss.; SALCEDO, E., o. c., p. 200 y ss.

47 Rabaté, J. C. y Colette, Miguel de Unamuno: biografía, Taurus, Madrid, 2009, p. 169.

48 Rousseau resuena con especial fuerza en estas ideas unamunianas; véase: RoussEAu, J. J., El contrato social, Alianza Editorial, Madrid, 2012. Como se ha dicho anteriormente, la época contemporánea puede considerarse el periodo donde el debate acerca de la identidad personal y la autenticidad cobran un protagonismo fundamental.

49 Un claro ejemplo: la figura del fariseo Nicodemo, que termina sucumbiendo en su búsqueda de Jesús.

50 Tanganelli, P., «Introducción a las Meditaciones Evangélicas de Unamuno», en: TaNGanelli, P. (ed), Meditaciones Evangélicas de Miguel de Unamuno, Diputación de Salamanca, Salamanca, 2006, p. 27.

51 Esta dialéctica y su evolución son la respuesta de Unamuno a las cosmovisiones nihilistas e historicistas que comienzan a aparecer en el panorama intelectual europeo y que sumen al ser de la persona en la mera historicidad, caducidad y teatralidad. Don Miguel se niega a reducir la vida humana a la mera circunstancia histórica; entiende que el intelectualismo, la político y la historia misma paralizan al hombre... por ello considera que hace falta un fuerza sobrenatural que permita al yo interno liberarse de todas esas losas. Vease: UNAMUNo, M., "Nicodemo el fariseo» en Tanganelli, P. (ed), Meditaciones Evangélicas de Unamuno, Diputación de Salamanca, Salamanca, 2006, p. 82. 
individuo. La eternidad de la intrahistoria es el espacio de la regeneración personal, de la conexión con la verdadera esencia de la persona. La historia, que antes era la de los hechos ruidosos e insustanciales, la del polvo de hechos, hoy es la historia del yo agónico que vive arrojado en el mundo y expuesto a su teatralización. Nuestro intelectual ve necesario poner la mirada en el yo eterno e intemporal, que sustenta al yo histórico; ese yo permanece en las realidades eternas, y no meramente fluye en las apariencias temporales como el histórico ${ }^{52}$.

\subsection{Cómo se hace una novela y el Unamuno maduro}

El periodo del destierro ${ }^{53}$ es probablemente uno de los más dramáticos en la vida del filósofo vasco; no solo por verse alejado de su tierra y seres queridos, sino también por la crisis que se le desencadenó al cuestionarse profundamente el sentido de la hazaña ${ }^{54}$. Don Miguel duda acerca de si realmente está siendo sincero o si, por el contrario, está representando un papel; «el Unamuno eterno se enfrentó con el histórico antojándosele fútiles sus preocupaciones y actuaciones políticas en comparación con el problema del alma, la muerte y la eternidad $»^{55}$. El filósofo teme que todo el asunto de la política y el destierro no sea más que vivir en una comedia, en un sentimiento cómico de la vida ${ }^{56}$.

Cómo se hace una novela refleja, pues, la constante preocupación unamuniana acerca de la relación entre la interioridad personal y la historia ${ }^{57}$. No obstante, don Miguel da un paso más en sus concepciones y se percata de que el alma ${ }^{58}$ y la historia no son tan antagónicas como pensaba en los tiempos de

52 Unamuno, M., «Nicodemo el fariseo», en: Tanganelli, P. (ed), Meditaciones Evangélicas de Unamuno, Diputación de Salamanca, Salamanca, 2006, p. 82.

53 Unamuno había sido una de las principales voces críticas a lo largo de todo el reinado de Alfonso XIII, y esto se agudizó en el momento en que el monarca consiente la dictadura del general Primo de Rivera. Don Miguel es exiliado a Fuerteventura, donde permanece durante un tiempo, hasta que se le permite volver a su casa; entonces, él mismo decide partir a un exilio voluntario en Francia como forma de denuncia de una situación política que él concebía inasumible. Para conocer esta etapa en profundidad vease: Rabaté, J. C. y Colette, Miguel de Unamuno: biografía, Taurus, Madid, 2009, pp. 451-555 y SAlcedo, Emilio, Vida de don Miguel, Anaya, Salamanca, 1964 pp. 250 y ss.

54 En París, Unamuno se descubre caricaturizado —incluso utilizado- y comienza a dudar de la efectividad y sentido del destierro voluntario en el que se había enrolado. Se percata del lado teatral de lo que hace y se da cuenta de que lo que busca proyectar no está siendo captado en la forma en que pretendía. Vease: ZubizArreta, A., Unamuno en su nivola, Taurus, Madrid, 1960, p. 60.

55 Gullón, R., Autobiografías de Unamuno, Gredos, Madrid, 1964, p. 289.

56 Ayala, F., «El arte de novelar de Unamuno», en La Torre, 9, 1961, pp. 329-359.

57 En la ficción, Jugo de la Raza se encuentra con un libro con un misterioso mensaje: «cuando termines de leerlo morirás». Jugo de la Raza es el mismo Unamuno que se encuentra ante la novela de su vida y la finitud de la misma. Sus actos son meras páginas de esa novela o ficción que un día acabará, pero, a la vez, tienen una fuerte carga existencial: pues son ellos los que permiten la ficción (vida) misma, los que la sustentan y la van desarrollando.

58 Entendida como «yo profundo/interno». 
Nicodemo el fariseo. Retomando intuiciones presentes ya en Paz en la Guerra ${ }^{59}$, comienza a atisbar una relación entre el «yo profundo» y la historia: El propio "yo interno» se va haciendo y rehaciendo con los acontecimientos políticos y sociales en los que está inmerso; de forma que tanto éste como la imagen proyectada exteriormente en la sociedad son genuinos. Teresa Gómez Trueba ${ }^{60}$ lo expresa muy claramente al afirmar que cree que el autor se muestra tan sincero al preguntarse si su representación era ficción, como cuando insistía en la sinceridad y en la necesidad del papel desempeñado. Y es que, Unamuno pretende transmitirnos que la formación de la auténtica personalidad implica sin remedio el movimiento dialéctico o eterno desplazamiento de un estado de ánimo a su contrario; el hacerse de la persona sería ahora, para él, como un proceso sintético entre el creerse haciendo un mero papel y el estar convencido de la autenticidad lo que se hace.

El intelectual se reafirma en la idea de que su papel histórico y público es sincero y no una comedia o caricatura. Se convence de que no es hipócrita y se da cuenta de que el permanecer firme en su postura es la única manera que tiene de hacerse a sí mismo, de elaborar su novela vital. Su papel es su verdad... y por lo tanto su postura a la contra ${ }^{61}$ es legítima, sin ella no sería él. Al igual que si Jugo termina la novela que está leyendo se muere, también si nuestro filósofo termina con el papel de desterrado y vuelve a España se muere. Haciendo su papel en la Historia, ve Unamuno que va haciendo la novela de su vida... y que no podría hacerlo de otra manera.

\section{QUIJOTISMO UNAMUNIANO}

El tercer centenario de la publicación del Quijote y de la muerte del Manco de Lepanto dio un gran auge a la obra cervantina entre los intelectuales españoles. Recordemos que estamos en una España que atraviesa por una profunda crisis y que necesita ahondar en lo profundo de su cultura como en busca de algo de luz y esperanza. La figura del hidalgo manchego tendrá también una importancia capital en la obra unamuniana.

A medida que su pensamiento avanza, también irá cambiando su valoración con respecto al Quijote. A modo general podemos distinguir dos etapas diferentes $^{62}$ : la del Unamuno anterior a la crisis y la posterior. Evidentemente, sus

59 Recordemos como los acontecimientos histórico-políticos también iban dando forma al intrahistórico hogar de Pedro Antonio y Josefa Ignacia.

60 Gómez Trueba, T., «Introducción a Cómo se hace una novela», en: Unamuno, M.Cómo se hace una novela, Gómez Trueba, T. (ed), Cátedra, Madrid, 2018, pp. 34-35.

61 Actitud públicamente contestataria ante la política española.

${ }_{62}$ Grady Seda Rodríguez también recoge esta evolución en el pensamiento de don Miguel con respecto al Quijote, sin embargo, la intelectual habla de tres etapas: 1) 1894-1905, 2) Vida de don Quijote y Sancho (1905), 3) 1906 en adelante. Mi posición no es diferente a la suya, a diferencia de que he optado por considerar Vida de don Quijote y Sancho y el periodo 
concepciones metafísicas acerca de la vida, la historia y la razón influirán de forma considerable en sendas valoraciones.

La lectura anterior a la crisis está íntimamente relacionada con su pensamiento panteísta-socialista. Las locuras quijotescas — las hazañas del caballero andante- son puestas en relación con la historia de España y con sus andanzas en el mundo en defensa de la fe católica principalmente. Alaba la muerte de Alonso Quijano abominando sus locuras, lo mismo que considera que España ha de renegar de ellas, para morir y posteriormente renacer; destaca la bondad de Alonso Quijano como el rasgo donde se revela el pueblo castellano intrahistórico, libre de todo casticismo particularista ${ }^{63}$.

La lectura posterior está ya transida por la preeminencia del "yo íntimo». En ella, se respiran los aires ${ }^{64}$ del Sentimiento Trágico y se caracteriza por una primacía de la vida frente a la razón. La locura es la manifestación más genuina de la autenticidad de la vida y de los anhelos del corazón y don Quijote pasa a convertirse en exponente y cumbre de esa locura.

Yendo más allá en esta segunda etapa, es necesario señalar el sentido utópico que la concepción unamuniana de la locura desprende. Ésta supondría una especie de ruptura con lo real, con lo histórico y temporal, produciendo la necesidad de acogerse a lo ideal. Laín Entralgo ha insistido con fuerza en la función que el ensueño ha desempeñado en todos los escritores del $98^{65}$. Ahora bien, tampoco ha de entenderse esto como un abandono de lo real, sino más bien como una lucha continua - a modo dialéctico- en la que ensueño y realidad se baten continuamente, volviendo siempre a la realidad misma.

Podemos decir que esta locura, hija de la actitud irracionalista, se caracteriza por poseer el rasgo valioso de toda utopía, es decir, la posibilidad crítica frente a la realidad ${ }^{66}$. Se trata de una negatividad crítica que en la España de su tiempo constituiría una provechosa sacudida frente a los inmovilismos reinantes ${ }^{67}$. Segundo Serrano Poncela señala de forma ilustrativa los alcances críticos del quijotismo unamuniano:

«En 1898 España aparece históricamente como un residuo, una oquedad, algo que fue, espectro deformado de un existir. Utilizando textos del mismo Unamuno, podríamos caracterizar a la España oficial y a buena parte de la

posterior como una misma etapa, ya que las ideas de Del sentimiento trágico de la vida están muy emparejadas con la mentada obra. Vease: SEDA Rodríguez, G., Unamuno: critic of Cervantes, Ann Arbor, Michigan, 1968.

${ }_{63}$ Los principales escritos quijotescos de esta época pueden encontrarse en En torno al casticismo y en los diferentes artículos y ensayos que Manuel García Blanco recogió en su edición de las obras completas publicada por la editorial Escilicer (tomos II, III y VII). Entre todos ellos, cabe destacar el artículo ;Muera don Quijote! que puede consultarse directamente en: https://gredos.usal.es/bitstream/handle/10366/84028/CMU_1-130. pdf? sequence $=1 \&$ isAllowed $=y$

${ }^{64}$ Empiezan a aflorar las ideas que cristalizarán en la elaboración de la obra citada.

65 Laín Entralgo, P., La generación del 98, Espasa, Madrid, 1997, p. 347.

66 Muy en la línea de Luciano de Samosata, Erasmo o Tomás Moro.

67 Díaz, E., Revisión de Unamuno, Tecnos, Madrid, 1968, p. 186. 
España comunal y mostrenca que vegeta sobre la península del siguiente modo: formas de vida ordenancistas y despersonalizadas, fanfarronería de miles gloriosus como residuo de un pasado militar activo, horror al trabajo, polarización entre la voluntad de arranque y el espíritu fatalista, sobre de individualidad y ausencia de personalidad, ausencia de libertad interior, monotonía vital traducida en atonía, tendencia a la disociación, ideofobia, ausencia de corrientes intelectuales, insociabilidad, pobreza e ignorancia presumida ${ }^{68}$.

En Vida de don Quijote y Sancho, Unamuno se vale del personaje cervantino para expresar los que él piensa y siente que son los principales males que afectan a la nación y a sus habitantes ${ }^{69}$. Se vale de escenas como aquella en que don Quijote es enjaulado por el canónigo y el barbero y llevado de nuevo a casa ${ }^{70}$ para criticar el "paralizador sentido común» que embota la nación igual que les embota a ellos y a la sobrina del hidalgo. El afán por la honra y la importancia dada a las apariencias impiden que el espíritu español se supere a sí mismo y despliegue toda su potencialidad; por ello, don Miguel anima a rebelarse los requerimientos sociales en busca de luz y de sentido. La locura libera de los miedos y frenos que la sociedad impone, adquiriendo de esa manera un claro carácter regenerador... no sólo para el país, sino en general.

Es también representativa la potente imagen de la cueva, que representa la tradición, en la que ninguno de los que se dicen tradicionalistas ha llegado nunca a adentrarse ${ }^{71}$. Los que se creen depositarios de la verdad y esencia de la patria son, para nuestro autor, los principales enemigos de ella... ya que pretender encorsetar y encapsular un espíritu que ni siquiera conocen. La tradición no consiste para Unamuno en una colección de reliquias del pasado ni en una retahíla de glorias del ayer, sino en el inconformismo de aquel que es capaz de ir más allá de lo normal y comúnmente aceptado siguiendo sus instintos de libertad. Por ello, don Miguel avisa del peligro de un tradicionalismo rancio o un progresismo hueco que en el fondo no son más que cobardía moral disfrazada.

Pero sobretodo son de gran importancia las lecturas que don Miguel hace del amor entre don Quijote y Dulcinea ${ }^{72}$, y de las consecuencias revitalizadoras y dotadoras de sentido que ese amor de cara a la vida y locura del hidalgo. El amor es el único capaz de crear sentido y finalidad a la vida humana, éste es el motor más genuino de la verdadera locura quijotesca.

El sentimiento trágico de la vida está en íntima sintonía con esta última parte de Vida de don Quijote y Sancho y, de hecho, recoge esta misma lectura del Quijote y de su locura. Allí, don Miguel se refiere a él como cima de la filosofía española, filosofía intrahistórica que es legado y misión de España de cara al mundo entero. Define a don Quijote como «la expresión de una lucha entre lo

68 Serrano Poncela, S., El pensamiento de Unamuno, Fondo de Cultura Económica, Madrid, 1953, p. 202.

69 Zambrano, M., Unamuno, Debate, Barcelona, 2003.

70 Unamuno, M., Vida de don Quijote y Sancho, Cátedra, Madrid, 2018, pp. 312 y ss.

71 Ibid., pp. 373 y ss.

72 Unamuno, M., Vida de don Quijote y Sancho, Cátedra, Madrid, 2018, pp. 478 y ss. 
que el mundo es, según la razón de la ciencia nos lo muestra, y lo que queremos que sea, según la fe de nuestra religión nos lo dice» ${ }^{73}$. Don Quijote, según el filósofo vasco, vive en nosotros y sigue «alentándonos con su aliento, animándonos a que nos pongamos en ridículo» ${ }^{74}$. Esto es, a confrontar lo real con la locura utópica de la idealidad.

Se observa, pues, que la oposición entre las dos lecturas es clara; tanto que incluso en Vida de Don Quijote y Sancho ${ }^{75}$ llega a arrepentirse de su visión anterior. La primacía del quijotismo (defensor de la vida por siempre) será clave para entender al segundo Unamuno... mientras que el racionalismo, el abandono de la locura y la inmersión en la bondad de la casta universal, que según la lógica socialista estaba por llegar, definirían al primero ${ }^{76}$. No obstante, la figura de don Quijote es aun así un eje constante del pensamiento y acción de Unamuno, tanto a nivel metafísico como político... desde él, trata don Miguel de entenderse a sí mismo y de entender a su país a lo largo de toda su obra.

\section{INDIVIDUALISMO CORDIAL}

Como ya se ha dicho, la crisis de 1897 supuso un verdadero punto de inflexión en el pensamiento unamuniano. El problema del sentido y finalidad de la vida individual pasaba a un primer plano en sus preocupaciones y, como consecuencia, las convicciones socialistas y panteístas fueron perdiendo fuerza. Nicodemo el fariseo o Vida de don Quijote y Sancho reflejan ya una cosmovisión totalmente diferente a los primeros ensayos de En torno al casticismo; Unamuno va desarrollando un pensamiento focalizado en el individuo y su libertad, el sentido de la vida y la muerte, en el cual el racionalismo comienza a ser fuertemente cuestionado debido a su incapacidad para responder a los anhelos existenciales del hombre ${ }^{77}$. Sin embargo, el tratado filosófico por excelencia de este segundo Unamuno es Del sentimiento trágico de la vida en los hombres y en los pueblos. En esta obra, el rector salmantino desarrolla ampliamente sus nuevos posicionamientos filosóficos, por lo que su comprensión —en conjunto con el Unamuno agónico y quijotesco- resulta fundamental para entender la etapa de madurez de don Miguel, y en lo que en este ensayo nos

73 Unamuno, M., Del sentimiento trágico de la vida, Cerezo Galán, P. (ed), Austral, Madrid, 2011 , p. 322 .

74 Ibid., p. 323.

75 Unamuno, M., Vida de don Quijote y Sancho, Cátedra, Madrid, 2018, p. 476.

76 Para una mayor profundización en este eje véase: Iglesias Granda, J. M., Sentir y pensar la historia con Miguel de Unamuno, Apeiron Ediciones, Madrid, 2019, pp. 73-95.

77 Amor y Pedagogía es clara enseña de este Unamuno, más que contrario al racionalismo, desengañado con él dada su tendencia a oscurecer y tapar los anhelos más típicamente humanos, que tarde o temprano afloran en toda vida. Vease: Unamuno, M., Amor y Pedagogía, Alianza, Madrid, 2008. 
atañe, para perfilar ese individualismo cordial $^{78}$ que caracterizará al Unamuno maduro y que está en íntima relación con el sustrato liberal-libertario que le acompaña desde su juventud.

El individualismo cordial de Unamuno se caracteriza por ${ }^{79}$ :

1) La importancia de la dimensión espiritual: comprende al hombre como un ser intermedio entre lo material y lo espiritual, de forma que todas sus dimensiones trascendentes se enmarcan en su existencia carnal pero, a la vez, son capaces de trascendentalizar a ese sujeto carnal convirtiéndolo en un sujeto de libertad.

2) La legitimidad de la voluntad: la voluntad adquiere estatus ontológico ya que es consecuencia del carácter trascendental del hombre. El sentido de la vida humana pasa de ser algo meramente desiderativo para considerarse desde una perspectiva ontológica.

3) El papel clave de la libertad: en íntima conexión con la voluntad, la libertad refleja el carácter trascendental y abierto de la vida humana. Es el distintivo principal de la persona humana.

4) La comprensión del hombre y de la Humanidad como tiempo y lugar de la divinización o salvación de toda la realidad.

De aquí, emerge toda una filosofía de la historia que entiende el devenir de la Humanidad en su conjunto como un proceso de unión del hombre con la Divinidad (apocatástasis). El deseo de eternizarse de cada persona se cumpliría no solo por medio de la realización de su vocación civil sino también por su colaboración - siguiendo los anhelos del corazón- en esa unión de todos con $\operatorname{Dios}^{80}$. Para Unamuno existe una tensión clara entre cultura (o civilización) y metafísica ${ }^{81}$ y, además, considera que es la misión histórica de España el mantenerla y enseñarla al resto de pueblos del mundo ${ }^{82}$.

En su valiosa revisión del pensamiento político unamuniano, Elías Díaz viene a señalar que filósofo vasco no llevó sus principios liberales hasta sus

78 Este cuarto eje es fundamental para comprender como Unamuno atisba y reacciona frente a los movimientos totalitarios que visitaron España a partir de los años 30 del siglo XX.

79 Estos rasgos han sido extraídos a partir del estudio introductorio a Del sentimiento trágico de la vida elaborado por el prof. Pedro Cerezo Galán. Vease: Unamuno, M., Del sentimiento trágico de la vida, Cerezo Galán, P. (ed), Austral, Madrid, 2011, pp. 26 y ss.

80 Recordemos que para Unamuno es la misma Humanidad la que va creando a Dios en su seno (a imagen de la virgen María) a partir de los anhelos profundos de su corazón... por lo tanto, cada hombre ha de colaborar en ese alumbramiento a fin de que la Humanidad llegue a su mete, a su plenitud y no caiga en el olvido.

81 Vease: Cruz CRUZ, J., «Tradición histórica y tradición eterna. De Ganivet a Unamuno», en: Anuario Filosófico, 31, 1998, pp. 261 y ss.

82 El matrimonio Rabaté recoge en su libro En el torbellino el testimonio existente acerca de la muerte de don Miguel. Según el joven falangista que la presenció, don Miguel hubiera expirando junto antes de exclamar: ¡Eso no puede ser! ¡Dios no puede volver la espalda a España!¡España tiene que salvarse! Expresión del todo en sintonía con su filosofía de la historia. Vease: Rabaté, J. C. y Colette, En el torbellino, Marcial Pons, Madrid, 2018, p. 193. 
últimas consecuencias democráticas debido a una espiritualización absorbente que le refrenaría en favor de los ideales religiosos ${ }^{83}$. Para el catedrático de la Universidad Autónoma de Madrid, la actitud de Unamuno de cara al final de la República y al comienzo de la Guerra Civil sería consecuencia de esa parálisis de raíz espiritual. Sin embargo, Pedro Cerezo Galán y Juan Marichal se muestran críticos con este posicionamiento ${ }^{84}$. Ambos filósofos, lejos de pensar en parálisis, hablan de una orientación espiritual total o de un dinamismo ético que confiere a Unamuno un carácter propio y que hace especialmente fructíferos a sus principios liberales. Yendo más allá, Cerezo Galán señala que Unamuno «muy tempranamente se apercibió de la uni-lateralidad de las formas de cultura que le tocó vivir, y reaccionó contra ello, dando batalla a lo uno y a lo otro, haciendo de la lucha la forma de su vida espiritual ${ }^{85}$. Y, precisamente, sus palabras terminan de definir a la perfección el individualismo cordial unamuniano, que carga con una profunda dimensión ética y existencial a los viejos principios liberales unamunianos y determina una actitud y compromiso políticos caracterizados por la actitud defensiva ante cualquier ideología o filosofía de la historia con visos totalitarios.

Conseguido esto, pasamos ahora a ocuparnos de los polémicos últimos meses de nuestro intelectual — quizás los más decisivos para una justa recepción de su pensamiento político-, de cara a los cuales el eje del individualismo cordial adquiere un importante papel hermenéutico.

A lo largo de la II República, Unamuno viene advirtiendo de los riesgos de la política de masas que se comienza a desarrollar. Si bien, don Miguel siempre se mantuviera crítico contra el catolicismo reinante en España, ahora contempla horrorizado los levantamientos anticatólicos que cristalizan en la quema de conventos e iglesias ${ }^{86}$. La República era, para él, el momento en que arraigaran las libertades individuales en el país, sin embargo, pronto constata lo mucho que tiene de respuesta violenta contra todo lo anterior. La conferencia «El momento político de la España de hoy» refleja a la perfección el contraste entre la situación del país y su individualismo cordial:

«Ahora el mundo va por otros derroteros: fascismo o comunismo que convertirán a los hombres en un inmenso rebaño, donde será tratado impíamente todo lo personal, todo lo individual. Hay que imponer el genio individual sobre la masa que todo lo invade y pretende centrar al mundo en el materialismo histórico. Siento no tener que decir sino esto: amigos, hasta otra ${ }^{87}$.

83 Díaz, E., Revisión de Unamuno, Tecnos, Madrid, 1968, pp. 96-97.

84 Cerezo Galán, P., Unamuno, ecce homo: la existencia y la palabra, Ediciones Universidad de Salamanca, Salamanca, 2016, pp. 170-171.

85 Ibid., p. 171.

86 Vease: Rabaté, J. C. y Colette, Miguel de Unamuno (1864-1936) convencer hasta la muerte, Galaxia Gutemberg, Madrid, 2019, pp. 418 y ss.

87 Unamuno, M., «El momento político de la España de hoy», en: Pascual Mezouita, E. (ed.), La política del último Unamuno, Ediciones Anthema, Salamanca, 2003, p. 290 (la cursiva es mía). 
La actitud de la mayoría de los jóvenes entrará, también, en fuerte contraste con su individualismo cordial. Nuestro intelectual siente una creciente lejanía hacia esas generaciones que se dejan encandilar por la política de masas, enterrando los anhelos de plenitud y libertad bajo ideales superficiales de utopía terrena ${ }^{88}$. Unamuno no reniega de su republicanismo, pero sí que concibe el régimen de la II República como un fracaso del liberalismo; y su enfrentamiento con Azaña ${ }^{89}$ y las políticas de su gobierno (regionalismo, cuestión religiosa) tienen mucho que ver con ello. Don Miguel denuncia el progresivo ascenso de fuerzas anti-liberales que convierten al régimen en política de masas y a los ciudadanos en mero rebaño ${ }^{90}$.

Es en este contexto en el que ha comprenderse el apoyo inicial de nuestro filósofo al levantamiento militar del general Franco, el cual generó una tremenda expectación ya en su momento y que terminó con la polémica cuita del Paraninfo el 12 de octubre de 1936. Todo parece indicar que el intelectual entendió el levantamiento como una manera de encarrilar el —para él- desastroso régimen republicano. Las ideas bolcheviques provenientes de Rusia y fuertemente reaccionarias frente al catolicismo tradicional español eran vistas con alarma por don Miguel $^{91}$; y es que hemos de tener en cuenta que su pensamiento ponía

${ }^{88}$ Se refiere a ellos como jóvenes de cuerpo pero con mentalidad de niño de cinco años. Para él, la degeneración espiritual de esa generación de militantes es espantosa. Vease: Carta de Miguel de Unamuno a Emma Clouard, archivo de Manuel García Blanco, CMU, 31/55, transcrita por Laurano Robles en: Unamuno, M., Epistolario inédito, vol. II, 1915-1936, RoBLES, L. (ed.), Austral, Madrid, p. 342.

Alicia Villar también hace alusión a la cuestión de la juventud en el estudio de su edición de Mi Confesión. Texto muy anterior a esta época (1904), pero que ya recoge la decepción del intelectual hacia los jóvenes. Vease: Unamuno, M., Mi confesión, Villar, Alicia (ed.), Sígueme, Salamanca, 2015.

89 Acerca de la relación y debate existente entre Unamuno y Azaña han corrido ríos de tinta. Don Miguel llegó a calificar al político republicano como un «resentido con talento que suponía un peligro para la nación». Y es que, Unamuno era un fuerte opositor de las políticas regionalistas que se llevaron a cabo en los gobiernos de Azaña; pues, éstas iban contra sus ideas acerca de la continuidad de la historia y de la patria española. Tampoco políticas religiosas agresivas, como la expulsión de los jesuitas, agradaron a Unamuno. Vease: RABATÉ, J. C. y Colette, En el torbellino, Marcial Pons, Madrid, 2018, pp. 24-29.

90 Recordemos que don Miguel fue diputado en las Cortes que elaboraron la Constitución Republicana, ocupando además diversos cargos políticos relacionados con la Educación. Sin embargo, a medida que su desencantamiento crece va apartándose y renunciando a sus cargos... replegándose más hacia su interior. Vease: SALcedo, E., Vida de don Miguel, Anaya, Salamanca, pp. 350 y ss.

Elías Díaz señala en Unamuno un espiritualismo absolutizador que le aleja de la lucha política, sin embargo, tanto las biografías como sus escritos nos dejan ver que no hubo un espiritualismo que le alienara de la realidad, sino más bien un profundo descontento con la misma que mezclado con el cansancio le hizo ir viviendo la política desde una perspectiva diferente. Ahora bien, nunca permaneció al margen de ella. Vease: Díaz, E., Revisión de Unamuno, Tecnos, Madrid, 1966.

${ }_{91}$ En una carta a su amigo el novelista griego Spiros Melas le narra fustigado el fetichismo existente en las masas que en España se habían unido a las ideas bolcheviques. Se refiere a ello así: «terrible demencialidad fetichista y materialista que rinde culto a Marx o a 
en íntima relación la identidad y misión de España con la cuestión espiritual y la civilización cristiana ${ }^{92}$. Esta defensa de la civilización cristiana -recordemos la unamuniana tensión entre civilización y metafísica- era uno de los puntos principales del programa de los sublevados ${ }^{93}$, quienes, además, tardaron en renegar de la República; posiblemente fuese esta una de las causas que lanzasen a Unamuno a apoyar el golpe. Sin embargo, el escritor pronto se percató de que las formas del Movimiento y del nuevo Estado instaurado estaban también bien lejanas de su individualismo cordial. El momento más representativo del choque entre el intelectual y el incipiente régimen de Franco es la citada celebración del 12 de octubre. El extremismo reaccionario que Unamuno tanto detestara de la parte republicana afloraba con igual fuerza en los partidarios del nuevo régimen quienes en sus discursos rechazaban a la otra parte del país como enemiga y propugnaban un nacionalismo étnico al estilo de aquel que primara a finales del siglo anterior en la época del Desastre. La intervención de don Miguel ese día tendrá consecuencias inminentes para su persona: esto es, la pérdida de su puesto y el encierro en su casa; pero a la vez reflejan con claridad cómo las ideas liberales del escritor no habían virado en ningún momento, sino que simplemente lo confuso de los acontecimientos sumado a su dialéctico y cordial de su individualismo le habían incitado a precipitarse equivocadamente ${ }^{94}$.

Desde entonces, la ausencia de cordura y racionalidad ${ }^{95}$ que caracteriza a la guerra sumada al extremismo reaccionario que dividía a las masas fueron generando en el intelectual un aislamiento espiritual voluntario que culminaría con su muerte. La España del sentimiento trágico no solo era incapaz de cumplir su misión enaltecedora de la vida, la libertad y los anhelos del corazón, sino que, se encontraba sumida en una lucha encarnizada a favor de ideales opuestos que poco tenían que ver con la verdadera esencia de su identidad. Junto con este individualismo cordial, afloran restos de la metafísica de su juventud: las ideas de intrahistoria, de polvo de hechos... pero con la diferencia de que ahora ya no prima la paz en la guerra, sino el resentimiento trágico.

Lenin y a la Virgen de su parroquia sin saber nada de ellos». Vease: Unamuno, M., Epistolario Inédito, Robles, L. (ed), vol. II, 1915-1936, Austral, Madrid, 1991, p. 342.

92 Aunque su comprensión del cristianismo genuinamente español poco tuviese que ver con el catolicismo (clericalismo) militante que finalmente terminaría prevaleciendo y aliándose con el nuevo poder.

93 Su comprensión de «civilización cristiana» era lejana a la de Unamuno. Ellos estaban en mayor sintonía con la cosmovisión clerical típica del catolicismo español que tanto denunció nuestro intelectual y que desde siempre ha ahogado a la religiosidad cristiana genuina de España.

94 Los artículos nunca publicados «Examen de conciencia» $\mathrm{y}$ «En el torbellino» tienen un claro carácter de confesión personal y reflejan el arrepentimiento del intelectual por haber tomado la opción de apoyar a los sublevados. Pueden leerse ambos artículos en: RABATÉ, J. C. y Colette, En el torbellino, Marcial Pons, Madrid, 2018, pp. 246-254.

95 Al igual que hiciera en la dictadura de Primo de Rivera, Unamuno acusa a los militares de odio a la inteligencia. Vease: Rabaté, J. C. y Colette, En el torbellino, Marcial Pons, Madrid, 2018, 138. 


\section{ConcLusiones}

A la luz de los cuatro ejes propuestos, quedan claras dos cuestiones principales: en primer lugar, el constante compromiso de Miguel de Unamuno para con España; y en segundo lugar, la impregnación metafísica del mismo. Imprescindible esta última para comprenderlo genuinamente.

Si el pensamiento español se ha caracterizado por ser eminentemente práctico -íntimamente ligado a la vida—, el filósofo vasco podría considerarse como uno de los principales exponentes del mismo. Más allá de su indudable vocación intelectual, don Miguel pensaba por necesidad; y esa necesidad, en muchas ocasiones convertida en lucha incesante, se prolongó durante toda su vida calando en todas y cada una de sus múltiples facetas.

La verdadera sabiduría se va adquiriendo progresivamente a lo largo de la existencia; a medida que la vida filosófica potencial en cada uno de nosotros se va desarrollando y desplegando como por estadios ${ }^{96}$. Unamuno es un claro ejemplo de esto. La historia que él vivió, pensó e hizo fue a la vez hacedora y maestra suya; en una relación como de retroalimentación en la que el intelectual la pensaba y actuaba en ella, a la vez que ella, en sus acontecimientos, le iba dando las píldoras de sabiduría que le permitían evolucionar y crecer espiritualmente. No estoy seguro de si él llegó a captar intelectualmente esta realidad, ya que su pensamiento dialéctico siempre le mantuvo en la batalla «yo profundo-yo histórico»; no obstante, si no llegó a hacerlo se quedó muy cerca, pues la conclusión de Cómo se hace una novela dista ya muy poco de esto.

Teniendo en cuenta esta evolución metafísica, se pueden distinguir claramente dos Unamunos: el anterior a la crisis —el del sentimiento eufórico- y el posterior a ella — anhelante de vida y de perpetuidad de su individualidadEsa crisis será el acontecimiento por excelencia que ofrezca a nuestro autor la píldora de realidad que le saque del socialismo panteísta y le confronte con los dilemas más profundos de la existencia humana y su sentido. Después de ella todo cambia; él no vuelve a ser el mismo, lo mismo que tampoco lo será su forma de pensar la política, la historia y la sociedad. Ahora bien, a pesar de este cambio drástico sería un error hablar de una discontinuidad total en el pensamiento político de ambos unamunos. Y es que, si algo caracteriza al filósofo vasco desde juventud es un cierto anarquismo, en el mejor sentido de la palabra, que le impide adherirse a pies juntillas a nada y que le lanza a criticar con fuerza, siempre de cara a una convivencia productiva, cualquier ideología con pretensiones de hegemonía. Hay, pues, un sustrato liberal-libertario que se mantiene intacto en toda la trayectoria unamuniana y que va siendo matizado en las diferentes épocas por la vida filosófica que el autor despliega en ellas.

La propia evolución existencial le hizo percibir y entender la problemática de su país de una forma totalmente diferente. Espiritualización absolutizadora — dirán algunos- . No obstante, este comprender la realidad desde una

96 García Baró, M., Filosofía como sábado, PPC, Madrid, 2015. 
perspectiva mucho más existencial no le apartó del compromiso político activo. Dejó de creer en las utopías socialistas, no confió más — si alguna vez lo hiciera- en el poder revolucionario; empero, concibió una nueva forma de transformar la sociedad: la de don Quijote; o sea, la de confrontar continuamente lo real y obvio dejándose llevar por el amor. Sin tener en cuanta esto, no se entendería el Unamuno del exilio, tanto en su producción intelectual como en el mero empeño de mantenerse combativo fuera de España voluntariamente.

Independiente y no sujeto a ninguna ideología, no dejó de clamar contra la injusticia y la corrupción y de defender lo verdaderamente humano. Le importaba el bien de sus compatriotas y le daba igual la pervivencia de cualquier sistema ideológico o político. Quizá esa libertad interior que da el tener puestas las preocupaciones en cuestiones atemporales fuese la que le confirió la verdadera libertad para ponerse en juego y dar la cara, cuando muy pocos lo harían -fijémonos en los polémicos últimos meses de su vida- Dio guerra con la pluma ${ }^{97}$, pero no solo; por ello hoy podemos considerarlo como uno de nuestros mejores maestros a la hora de afrontar nuestra tarea personal de repensar la historia.

Instituto de Filosofía CSIC

José Manuel Iglesias Granda

[Artículo aprobado para publicación en febrero de 2020]

97 Frase típica de Don Miguel, que emplea en muchos de sus escritos; aunque con especial interés en Paz en la Guerra, donde la identifica con la misión del intelectual. 